\title{
PRECIPITATING FACTORS CONTRIBUTING SEVERE HYPOGLYCEMIA AMONG TYPE-2 DIABETIC PATIENTS ADMITTED IN A TERTIARY CARE HOSPITAL OF BANGLADESH
}

\author{
Rushda Sarmin Binte Rouf ${ }^{1}$, Md. Faruque Pathan ${ }^{2}$
}

\begin{abstract}
Background: Hypoglycemia is the commonest acute emergency in the diabetic population. This study intends to find out the factors precipitating severe hypoglycemia in type-2 diabetes patients admitted in a tertiary care hospital in Bangladesh.

Methods: This cross-sectional study was conducted among 311 diabetic patients admitted in BIRDEM general hospital with hypoglycemia (plasma glucose concentration of $<70 \mathrm{mg} / \mathrm{dl}$ or $3.9 \mathrm{mmol} / \mathrm{l}$ ) with or without altered level of consciousness or neurological recovery of the patient occur after normalization of blood sugar, from a period of March 2014 to April 2015. After obtaining informed written consent a questionnaire focusing on the probable factors of severe hypoglycemia was supplied to the subjects or attendants at bedside. Relevant reports were collected from record book.
\end{abstract}

Results: Mean age of the study respondents was 49.02( \pm 15.99$)$ years which ranged from 18 to 90 years with male predominance (59\%). Mean duration of diabetes was 8.5( \pm 5.4$)$ years with range from 3 to 15 years. Majority (85.5\%) had more than 6.5\% of HbA1c. Severe hypoglycemia was revealed mostly (61.41\%) in insulin users. Among them 74(33.5\%) and 79(35.7\%) patients were using premixed and self mixed regimes respectively. Factors causing severe hypoglycemia were assessed by multivariate analysis. Significant association was found in meal related factors $(p<0.001)$ (missed meal, delayed or inadequate meal), insulin related factors $(p<0.001)$ (Newer dose, miscalculation, faulty technique, defective absorption). Other factors were renal impairment ( $p<0.001)$, gastroparesis $(p<0.01)$ and aging $(p=0.04)$.

Conclusion: Lifestyle factors are the most important precipitating causes of hypoglycemia. Therefore, appropriate diabetic education including self adjustment and periodic re-evaluation of patient's knowledge, attitude and practice towards hypoglycemia is of utmost importance to prevent this common but life-threatening complication.

Received: 24 September 2018

Accepted: 05 November 2018

DOI: https:// doi.org/10.3329/bjmed.v30i1.39920

\section{Introduction}

Hypoglycemia is the most feared and a common barrier in achieving strict glycemic control. This was observed in two landmark studies, the Diabetes Control and Complications Trial (DCCT, 1997) and U.K. Prospective Diabetes Study (UKPDS, 1998), which demonstrated the benefits of early intensive glycemic control in type 1 and type 2 diabetes, respectively. ${ }^{1,2}$ Large clinical trials have shown significant cardiovascular and cerebrovascular morbidities associated with hypoglycemia. ${ }^{3}$ Hence individualized targets of glycemic status has been emphasized by American Diabetes Association(ADA) particularly in patients with long duration of DM and co morbidities to reduce the risk the hypoglycemia. $^{4}$

1. Registrar, Department of Endocrinology, Bangladesh Institute for Research and Rehabilitation in Diabetes, Endocrine and Metabolic Disorders (BIRDEM), Dhaka, Bangladesh.

2. Professor and Head, Department of Endocrinology, Bangladesh Institute for Research and Rehabilitation in Diabetes, Endocrine and Metabolic Disorders (BIRDEM), Dhaka, Bangladesh.

Address of Correspondence: Dr. Rushda Sarmin Binte Rouf, FCPS, MD, Registrar, Department of Endocrinology, Bangladesh Institute for Research and Rehabilitation in Diabetes, Endocrine and Metabolic Disorders (BIRDEM), Dhaka, Bangladesh. E-mail-rushdalubna767@gmail.com. 
According to ADA (2013) severe hypoglycemia is an event requiring assistance of another person to administer actively carbohydrate, glucagon or other resuscitative actions. Plasma glucose measurements may not be available during such an event, but neurological recovery attributable to the restoration of plasma glucose to normal is considered sufficient evidence that the event was induced by a low plasma glucose concentration. ${ }^{10}$ The symptoms of hypoglycemia are markedly varied. Florid symptoms can develop in normal range of blood sugar in long standing poorly controlled groups where as it may be nonspecific or less intense even in severe hypoglycemia with increasing age, in type 1 diabetic or recurrent attacks of hypoglycemia and with autonomic neuropathy. ${ }^{5}$

In 2014 American Association of Clinical Endocrinology conducted a survey on symptomatic hypoglycemia among 2530 type 2 diabetic patients in USA which revealed about half of the study population were unaware of the precipitating factors and sequel of symptomatic hypoglycemia. ${ }^{6}$

In this background, awareness and knowledge regarding factors causing hypoglycemia need to be addressed properly to prevent recurrence of hypoglycemia in future. So, we conducted this study to reveal the precipitating factors of severe hypoglycemia among type 2 diabetic patients admitted in a tertiary care hospital (BIRDEM) of Bangladesh.

\section{Materials and Methods}

This cross-sectional study was conducted among the diabetic patients admitted in BIRDEM general hospital with hypoglycemia (plasma glucose concentration of $<70 \mathrm{mg} / \mathrm{dl}$ or $3.9 \mathrm{mmol} / 1$ ) with or without altered level of consciousness or neurological recovery of the patient occur after normalization of blood sugar from a period of March 2014 to April 2015. Hypoglycemia in non diabetic and pregnant women was not approached for the study. Sample size was calculated at $95 \%$ confidence interval with $5 \%$ precision which arrived 164 using prevalence $70 \% .^{7}$

After obtaining informed written consent from the subjects after recovery or attendants a questionnaire was given to be filled up. The questionnaire was focused on all the probable factors of severe hypoglycemia. Relevant reports were collected from record book. This study was approved by the ethical committee of the institution.

\section{Results:}

Total 339 patients were approached in the study. Of them 18 refused to be enrolled. Data from the remaining 311 patients were collected.
Table-1

Baseline Characteristics of the population $(N=311)$

\begin{tabular}{lc}
\hline Baseline characteristics & Number (\%) \\
\hline Age(years) & \\
$<50$ & $141(45.33)$ \\
$>50$ & $170(54.66)$ \\
Mean \pm SD : & $49.02( \pm 15.99)$ \\
Sex & \\
Male & $184(59)$ \\
Female & $127(41)$ \\
Distribution of area of residence & \\
Urban & $211(67.84)$ \\
Rural & $100(32.15)$ \\
Education & \\
$<$ Higher secondary school certificate & $231(74.3)$ \\
$>$ Higher secondary school certificate & $80(25.7)$ \\
Duration Of DM & \\
$<10$ years & \\
$>10$ years & $189(60.77)$ \\
Mean \pm SD : & $122(39.22)$ \\
Glycemic statusHbA & $<7 \%$ \\
HbA1c $>7 \%$ & $8.5( \pm 5.4)$ \\
Mean \pm SD : & $45(14.5)$ \\
$<2.8$ & $255(85.5)$ \\
Mean \pm SD & \\
\hline & \\
& \\
\hline &
\end{tabular}

Mean age of the study respondents was 49.02( \pm 15.99$)$ years with male predominance (59\%). Mean duration of diabetes was $8.5( \pm 5.4)$ years. Majority $(85.5 \%)$ had more than $6.5 \%$ of $\mathrm{HbA} 1 \mathrm{c}$. (Table-1)

Table-II

Association of treatment modalities with hypoglycemia $(N=311)$

\begin{tabular}{lccc}
\hline & Total & $\begin{array}{c}\text { OR; } \\
95 \% \mathrm{CI}\end{array}$ & $\begin{array}{c}\mathrm{p} \\
\text { value }\end{array}$ \\
\hline Only OAD & $90(30.20)$ & $2.20(1.11-4.35)$ & 0.02 \\
Only Insulin & $183(61.41)$ & $0.40(0.20-0.79)$ & 0.007 \\
OAD+Insulin & 38(8.39) & $1.06(0.43-2.65)$ & 0.89 \\
\hline
\end{tabular}

Treatment modalities are shown in table-2. Severe hypoglycemia was revealed mostly $(61.41 \%)$ in insulin users. Rest were on OAD (30.2\%) and OAD plus insulin $(8.39 \%)$ respectively. 


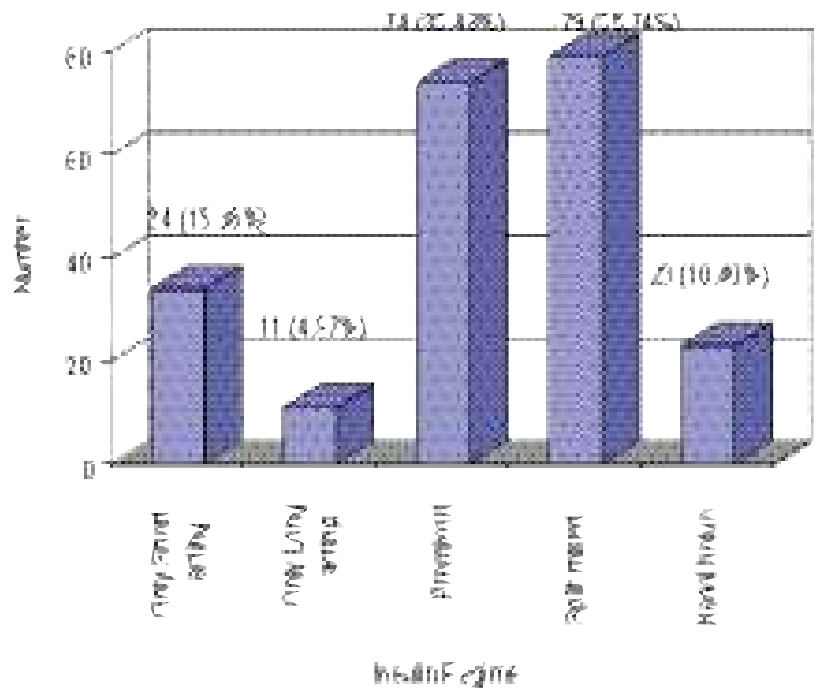

Fig.-1: Frequency of different insulin regimes in the study population $(n=221)$

In figure 1 frequency of different insulin regimes are shown. Hypoglycemia was more frequent those using premixed $(33.5 \%)$ and self $\operatorname{mixed}(35.7 \%)$ regimes respectively. Least $(4.97 \%)$ was observed in patients with long acting analogue only.

Table-III

Factors responsible for hypoglycemia in the study subjects $(N=311)$

\begin{tabular}{lccc}
\hline Factor responsible & Total & $\begin{array}{c}\text { OR; } \\
95 \% \text { CI }\end{array}$ & p value \\
\hline Meal related factor & 204 & $2.95(1.69-5.12)$ & $<0.001$ \\
Insulin related factor & 71 & $4.69(1.81-12.19)$ & $<0.001$ \\
Unaccustomed & 40 & $1.13(0.49-2.59)$ & 0.76 \\
physical exertion & & & \\
Ageing (>50) & 28 & $3.95(0.91-17.10)$ & 0.04 \\
Autonomic & 34 & $5.0(1.16-21.44)$ & 0.01 \\
Neuropathy & & & 0.48 \\
CLD & 14 & $1.71(0.37-7.85)$ & 0.001 \\
CKD & 69 & $11.39(6.96-18.65)$ & $<0.001$ \\
\hline
\end{tabular}

Factors causing severe hypoglycemia were assessed by multivariate analysis. Significant association was found in meal related factors $(\mathrm{p}<0.001)$ (missed meal, delayed or inadequate meal), insulin related factors $(\mathrm{p}<0.001)$ (Newer dose, miscalculation, faulty technique, defective absorption etc). Other important factors were renal impairment $(\mathrm{p}<0.001)$, gastroparesis $(\mathrm{p}<0.01)$ and aging $(\mathrm{p}=0.04)$. (table-III)
Table-IV

Knowledge and practice regarding hypoglycemia among the participants * $(N=311)$

\begin{tabular}{lc}
\hline Factors & $\mathrm{n} \mathrm{( \% )}$ \\
\hline Symptoms of hypoglycemia & $220(70.73 \%)$ \\
Precipitating factors & $130(41.80 \%)$ \\
Immediate management during & $187(60.12 \%)$ \\
an episode & \\
Complication of hypoglycemia & $102(32.79 \%)$ \\
Importance of SMBG to prevent & $94(30.22 \%)$ \\
further attacks & \\
Maintaining fixed meal plan & $96(31.68 \%)$ \\
\hline
\end{tabular}

*Multiple responses allowed

Knowledge and practice regarding hypoglycemia was assessed among the participants in table-4. Majority $(70.73 \%)$ knew about the common symptoms (sweating, palpitation, headache, dizziness). Immediate management (at least one remedial measure) during a hypoglycemic episode was known to $60.12 \%$. Precipitating factors (at least one) was known to $41.80 \%$ whereas only $32.79 \%$ were aware of the complication related to severe hypoglycemia. Very few (30.22\%) had the understanding of self monitoring of blood glucose to prevent hypoglycemia. Only $31.68 \%$ were on a fixed meal plan.

\section{Discussion:}

Key component of Diabetes care is to maintain target blood sugar to prevent or delay diabetes related complication. However, iatrogenic hypoglycemia is a major barrier to achieve this. In this hospital based study three hundred and eleven diabetic patients with hypoglycemia were included. Among them 184 were male $(59.2 \%)$ and rest were female (40.8\%). Highest percentage $(33.3 \%)$ of patients belonged to the age group of 51 to 60 years. Several studies also support this finding. $(3,7,8)$. It indicates extreme age is an important factor of hypoglycemia. This might have been because of age related cognitive impairment, multiple co morbidities, attenuated sympathoadrenal response to hypoglycemia. This study found no statistically significant difference between incidence of hypoglycemia in between demographic distribution, however the incidence was much higher $(74.3 \%)$ in less educated persons than who are highly educated. Better communication and repeated discussion appropriate to patient's literary level may reduce the risk. Although low literacy is a risk factor for severe hypoglycemia, it is presumably modifiable. Duration of diabetes was not found statistically significant. In this study more than eighty percent patients who 
experienced severe hypoglycemia had Hba1c $>7 \%$. Similar reports found in a study based on Hba1c and hypoglycemia(9). Possible explanation might be lack of proper self management education in this class of subject. In Chicago, June 2013 , ADA described association between $\mathrm{Hba} 1 \mathrm{c}$ with self reported hypoglycemia though no causal pathways between this two were established. They concluded hypoglycemia was common irrespective of glycemic status. ${ }^{(10)}$

Association of treatment modalities with hypoglycemia revealed a significant association with patients treated with insulin. Among them overall $60 \%$ were treated with premixed and self mixed regimes whereas only long acting insulin user had significantly lower frequency of hypoglycemia (4.97\%). The hallmark study by UKPDS found $70-80 \%$ of hypoglycemic episodes in insulin treated patients ${ }^{(2)}$. Other larger trial ACCORD and ADVANCE who found fatal vascular outcomes in intensively treated patients with insulin following hypoglycemia. ${ }^{(3,11)}$ Appropriate insulin technique and self adjustment was not properly addressed in this study population which might develop such remediable events.

Factors considered to be responsible for hypoglycemia were assessed in this study which demonstrated missing meals and insulin related factors eg; intensification of dose, error by patient or physician, miscalculation of dose, faulty technique, deliberate overdose, injection site issue were most common. Though commonest but these factors are presumably modifiable by collaborative approach. Background diseases contributed to severe hypoglycemia were renal and liver impairment. It is known that exogenous insulin remains in longer duration with unpredictability as renal and hepatic metabolism declines and contribution of glucose through gluconeogenesis is also reduced which causes recurrent hypoglycemia $(12,13)$. In this study $22.18 \%$ had renal impairment and $4.5 \%$ had hepatic dysfunction. Autonomic neuropathy was found to be another important precipitating factor $(\mathrm{p}$ 0.01) in this study. Autonomic neuropathy associated hypoglycemic unawareness is another alarming situation which should be addressed by physician with great emphasis to prevent severe hypoglycemia induced fatal outcomes. $(14,15)$

Even though most diabetics in this study had more than 5 years of duration, knowledge on hypoglycemia was not satisfactory. More than half knew about symptoms and what to do while an episode. Less than half knew what were the precipitating factors for severe hypoglycemia, only $32.79 \%$ were aware of complications related to it. Very few (30.22\%) knew SMBG as an appropriate tool to prevent further attacks by self adjustment. Education for patient empowerment should be emphasized for better understanding on self management strategies. Particularly the interactive relationship of hypoglycemia with their medication, meal plan, physical activity and special situation like sick days management should be clearly explained to limit hypoglycemic episodes thus improving standard of living in diabetics. (16)

\section{Conclusion:}

In most of the cases, lifestyle factors are the precipitating causes of hypoglycemia, which are readily recognizable and easily modifiable. Therefore, appropriate diabetic education and periodic reevaluation of patient's knowledge, attitude and practice towards hypoglycemia is of utmost importance to prevent this common but life-threatening complication.

\section{References:}

1. Diabetes control and complications trial research group. Hypoglycemia in the Diabetes control and complications trial. N Engl J Med. 1997; 329 : 977-86.

2. Prospective diabetes study group (UK). Intensive bloodglucose control with sulfonylureas or insulin compared with conventional treatment and risk of complication in patients with type2diabetes. Lancet. 1998; 352: 8373..https://doi.org/10.1016/S0140-6736(98)07019-6

3. Advance collaborative group. Intensive blood glucose control and vascular outcomes in patients with type 2 diabetes. N Engl J Med. 2008; 358: 2560-72. https:// doi.org/10.1056/NEJMoa0802987.PMid:18539916

4. American diabetes association. Standards of medical care in diabetes. Diabetes Care. 2014;37 :14-80..https:/ /doi.org/10.2337/dc14-S014.PMid:24357209

5. Cryer PE, Axelrod 1, Grossman AB, Heller SR,Montori VM, Seaquist ER, et al . Evaluation and management of adult hypoglycemic disorders: An Endocrine Society Clinical Practice Guideline. J Clin Endocrinol Meta. 2009; 94(3): 709-28..https://doi.org/10.1210/jc.20081410. PMid: 19088155

6. Survey Reveals Low Hypoglycemia Awareness Among Patients with Diabetes. Endocrine Today, May 2011. American Association of Clinical Endocrinologists 20 th Annual Meeting. Available from: http:// www.healio.com/endocrinology/diabetes/news/print/ endocrine-today/\%7Be3d5b9ab-65d9-4796-890b3b69df497be4 \%7D/survey-reveals-low-hypoglycemiaawareness-among-patients- with-diabetes. [Last accessed on 2014 Aug 22]

7. Vanessa J, Briscoe, Stephen N, Davis. Hypoglycemia in type 1 and type 2 diabetes: Physiology, pathophysiology and management. Clinical diabetes. 2006; 302: 115-121.

8. Leese G.P, Wang J, Kelly P,Bromhall J, Marsden A, Morrison W, et al. Frequency of severe hypoglycemia 
requiring emergency treatment in Diabetes .Diabetes Care. 2003; 26: 1176-80. https://doi.org/10.2337/ diacare.26.4.1176

9. Lipska K.J, Warton EM, Huang ES,Moffet HH, Silvio EI,Krumholz HM, et al. HbA1c and risk of severe hypoglycemia in type 2 diabetes. Diabetes Care. 2013; 36: 3535-42. https://doi.org/10.2337/dc130610.PMid:23900589 PMCid:PMC3816866

10. American Diabetes Association. Hypoglycemia and Diabetes: A report of a workgroup of the American diabetes association and the endocrine society. Diabetes Care. 2013; 36: 1384-1395. https://doi.org/ 10.2337/dc12-2480.PMid:23589542 PMCid: PMC3631867

11 Action to Control Cardiovascular Risk in Diabetes Study (ACCORD) Group. Effects of intensive glucose lowering in type 2 diabetes. N Engl J Med. 2008; 358: 25452559. https://doi.org/10.1056/NEJMoa0802743. PMid:18539917 PMCid:PMC4551392

12. Ajay K, Parsaik D, Rickey E,Pattan V, Myers LA,Kumar $\mathrm{H}$, et al. Population-based study of severe hypoglycemia requiring emergency medical service assistance reveals unique findings. J Diabetes Sci Technol. 2012; 6: 6573.https: / / doi.org/ 10.1177/ 193229681200600109 PMid:22401324 PMCid:PMC3320823

13. Gerich JE, Meyer C, Woerle HJ, Stumvoll M . Renal gluconeogenesis: its importance in human glucose homeostasis. Diabetes Care.2001; 24: 382-391. https:/ /doi.org/10.2337/diacare.24.2.382.PMid:1 1213896

14. Amiel SA, Sherwin RS, Simonson DC, Tamborlane WV. Effect of intensive insulin therapy on glycemic thresholds for counter regulatory hormone release. Diabetes. 1988; 37: 901 -907. https://doi.org/ 10.2337/diab.37.7.901.PMid:3290007

15. Dagogo-Jack SE, Craft S, Cryer PE. Hypoglycemiaassociated autonomic failure in insulin-dependent diabetes mellitus. J Clin Invest. 1993; 91: 819-822. https:// doi.org/10.1172/JCI1 16302.PMid:8450063 PMCid:PMC288033

16. Belinda P, Childs P, Jolene M,Pamela J. Strategies to Limit the Effect of Hypoglycemia on Diabetes Control: Identifying and Reducing the Risks. Clinical Diabetes. 2012; 30: 36-39. 